\title{
VIOLÊNCIA DOMÉSTICA E FAMILIAR CONTRA A MULHER: CONSTRUÇÃO DO PERFIL DAS VÍTIMAS DA COMARCA DE CAMPINA GRANDE/PB
}

\author{
Ana Virgínia Pereira do Nascimento ${ }^{1}$ \\ Célia de Castro ${ }^{2}$
}

Resumo: Este artigo tem como propósito analisar o perfil socioeconômico das vítimas de violência doméstica da comarca de Campina Grande/PB que possuem medida protetiva, que estão sendo acompanhadas pelo Juizado de Violência Doméstica e Familiar contra a mulher, da referida cidade. A pesquisa de campo será do tipo quanti-qualitativa, com base no método de análise crítico-dialético, conduzida através da aplicação de questionários estruturados fechados, realizados individualmente com as vítimas de violência que concordaram em participar da pesquisa. Os dados serão analisados através da técnica de análise de conteúdo. Pode-se observar que ao longo dos anos têm-se aumentado os índices de violência doméstica na cidade de Campina Grande/PB, então, após análises dos dados, buscaremos compreender qual o perfil destas vítimas e qual sua opinião em relação ao papel da medida protetiva na sua proteção, e como estão sendo garantidos os direitos instituídos pela Lei 11.340/2006.

Palavras-chave: Perfil socioeconômico; Medida Protetiva; Violência Doméstica.

1 Graduanda em Serviço Social/ Universidade Estadual da Paraíba - UEPB, Brasil. E-mail: annavirginia.p@gmail.com.

2 Mestre em Sociologia pela Universidade Federal da Paraíba, Brasil/ Professora da Universidade Estadual da Paraíba - UEPB, Brasil. E-mail: celiacastroprof@hotmail.com. 